\title{
The interplay between stress, circadian clocks, and energy metabolism
}

\author{
Henrik Oster (i) \\ Institute of Neurobiology, University of Lübeck, Lübeck, Germany
}

Correspondence should be addressed to H Oster: henrik.oster@uni-luebeck.de

\begin{abstract}
Endogenous circadian clocks adapt an organism's physiology and behavior to predictable changes in the environment as a consequence of the Earth's rotation around its axis. In mammals, circadian rhythms are the output of a ubiquitous network of cellular timers coordinated by a hypothalamic master pacemaker. Circadian clock function is closely connected to the stress response system which has evolved to ensure survival under less predictable situations of danger. Disruptions in both of these functions are highly prevalent in modern society and have been linked to pathologic alterations in metabolic setpoints, promoting overeating, obesity, and type-2 diabetes. This paper describes the different levels of interaction between the circadian clock and acute and chronic stress responses. It summarizes studies assessing clock-stress crosstalk in the context of metabolic homeostasis and outlines options to use this interaction for diagnostic and therapeutic measures targeting metabolic health and well-being in the highly chronodisruptive environment of modern 24-h globalized societies.
\end{abstract}

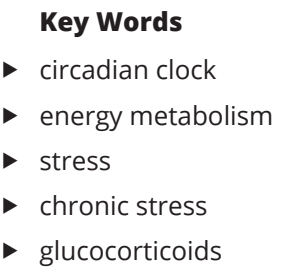

Journal of Endocrinology (2020) 247, R13-R25

\section{Introduction}

For most animals - and throughout most of evolution this planet has been a very dangerous place. Nutrients were scarce and often difficult to find. At the same time, predators were roaming the same habitats. Only those individuals capable of utilizing sufficient amounts of energy to acquire food, avoid predation, and secure mating partners were able to transmit their genetic information to the next generation. Several regulatory systems have emerged during evolution that promote the availability of energy at times of need while minimizing overall energetic needs at other times. Two of these, the stress system and the circadian clock, work closely together for this goal, but use fundamentally different principles of activation. The stress response is a fast, demand activated program that is essential for survival in unpredictable danger situations (Ellis \& Del Giudice 2019). In contrast, the circadian clock is a gradual, endogenously activated function that helps to anticipate predictable environmental changes brought about by the Earth's rotation around its axis, and thus, the 24-h succession of day and night (Pittendrigh 1993).

Besides their impact on various other aspects of physiology, both systems converge on the regulation of energy metabolism (Ramsey et al. 2007, Ford et al. 2017). In our modern societies, both are subject to frequent deregulation, be it from complex social interactions and environmental demands in the case of the stress system or nocturnal light pollution and sleep-wake rhythm disruption in the case of the circadian clock. Ultimately, these perturbations synergize in their disruption of metabolism and energy homeostasis, arguably among the key medical challenges of the twenty-first century (Herold et al. 2015).

This short review summarizes the main regulators of stress and clock systems in mammals with a focus on their 
mutual interaction in the regulation of energy metabolism. It highlights the detrimental effects of modern lifestyles on this interaction and suggests approaches to stabilize stress-clock-metabolism balance as a fundamental aspect of physiologic and psychologic well-being.

\section{Evolutionary aspects of stress systems}

In an acutely dangerous situation, our body needs to rapidly mobilize danger response systems to evade the risk of injury or even death. Sensory perception is increased, energy equivalents are mobilized and oxygen supplies to nervous and muscle tissues are upregulated. In consequence, stress promotes the accelerated depletion of energy stores due to an increase in energy expenditure. Ideally, such transient boost of energy turnover enables the organism to quickly evaluate the potential danger and initiate an appropriate fight-or-flight response. After the resolution of the situation and the neutralization of the challenge or danger, the stress system returns to baseline levels allowing for rest, regeneration, and the replenishment of energy stores (Russell \& Lightman 2019).

At the physiological level, the stress response comprises two different components (Tsigos et al. 2000). The first involves central and systemic autonomic activation and the release of catecholamines - adrenaline and, to a lesser extent, noradrenaline - from the adrenal medulla (Wong 2006). This fast/acute response is trailed by an activation of the multi-step hypothalamus-pituitary-adrenal (HPA) axis and the release of glucocorticoids (GCs) - cortisol in humans and other primates, corticosterone in rodents with a delay of several minutes (Kirschbaum et al. 1993). Consequently, also the downstream effects of these two endocrine stress effector systems show very different temporal kinetics. Catecholamines are highly soluble molecules that are stored in vesicles in the adrenergic medulla. Upon stress, these vesicles fuse with the plasma membrane and simultaneously release large amounts of molecules into the bloodstream (Douglas \& Rubin 1961). Once reaching their target tissues, catecholamines signal through activation of G-protein-coupled plasma membrane receptors and rapid second messengermediated signal transduction. GCs, on the other hand, are highly lipophilic. HPA axis activation promotes de novo synthesis of GCs from cholesterol. These then enter the bloodstream via diffusion through the mitochondrial and plasma membranes of adrenocortical cells (Turcu \& Auchus 2015). In the blood, GCs - because of their lipophilic nature - need to be transported by specific transporter proteins such as transcortin and albumin. At target tissues, GCs pass the plasma membrane to bind type-1 nuclear receptors that, after dimerization and nuclear translocation, act as transcription factors to affect cellular physiology through alterations in the enzymatic repertoire (Timmermans et al. 2019). This GC-mediated response takes minutes to hours to complete, making it less suited for fight-or-flight responses, but rather for intermediate-term adaptations to a stressful environment.

Both response systems share several targets, but while the autonomic/catecholaminergic response primarily affects the sensory and cardiovascular system, the endocrine axis/GC response mainly promotes the redistribution of energy equivalents while at the same time suppressing digestive and immune functions, two other biological systems of high energy demand (Tsigos et al. 2000).

When the organism experiences repeated or longlasting stressful situations, regulation of the stress system is chronically altered (McEwen 2017). During evolution, such extended stress situations were confined to unique events such as pregnancy or extreme environmental conditions. The complex demands of modern societies, however, have changed this situation fundamentally. The stress system adapts to ongoing psychosocial stimulation by rebalancing its two effector functions, promoting constant low-level activation of the autonomic system and a rebalancing of the negative feedback system controlling HPA axis function (McEwen 2017). Excitatory amino acids such as glutamate have a key function in the central adaptation to chronic stress. Excess glutamate release during chronic restraint stress in rodents leads to shrinkage of apical dendrites in neurons of the hippocampus (McEwen 2016) and the prefrontal cortex (Martin \& Wellman 2011) - two sites that also show robust functional circadian regulation (Chen et al. 2016, Snider et al. 2018). Activation of autonomic networks (Thome et al. 2017) and the sympathetic outflow from the brain is an important mediator of acute and chronic stress-induced disorders such as hypertension, obesity, and heart disease (Hering et al. 2015). Repeated exposure to the same stressor can result in habituation of HPA axis function, for example, decreasing GC responses over time, which requires active mineralocorticoid receptor (MR) signaling (Cole et al. 2000). Chronic exposure to stressors that involve non-social interventions (e.g. repeated immobilization or footshocks) leads to an upregulation of Crh mRNA expression in the PVN (Imaki et al. 1991, Mamalaki et al. 1992, Herman et al. 1995, Figueiredo et al. 2003). In parallel, chronic variable stress reduces 
GR in this area (Herman et al. 1995, Makino et al. 1995). Together, these two effects blunt the negative feedback of GCs on HPA axis regulation underlying elevated baseline GC concentrations characteristic for chronic stress adaptation. In consequence, chronic stress exposure increases tonic, but at the same time decreases phasic GC output from the HPA axis. On the long run, cardiovascular function, metabolic homeostasis, and central mood and motivation systems suffer from this, increasing the risk of developing chronic diseases such as arteriosclerosis, obesity, and major depression, respectively (Huang et al. 2013).

\section{Stress and metabolism - acute vs chronic effects}

Stress signals elevated energy demands to the body. From this perspective, the first-glance contradictory effects of acute and chronic stress on the regulation energy homeostasis start to make sense. In an acute stress situation, the body needs fast energy to fuel sensory perception, cognitive processing, and muscle activity in the fight-or-flight response. Taking in additional energy in the form of food would rather distract from this task and, hence, appetite and digestive metabolic functions are suppressed (Fig. 1). This changes under chronic stress conditions. While the body continues to fuel additional energy into cognitive and muscle systems,

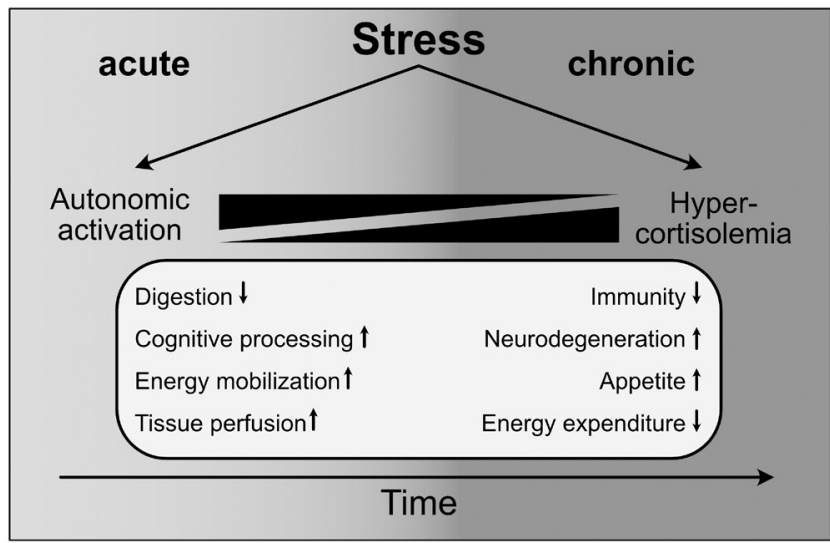

\section{Figure 1}

Physiological responses to acute and chronic stress. During acute stress, autonomic effects aim at mobilizing energy resources to enable the fight-or-flight response and evade imminent danger. Under repeated or chronic stress exposure endocrine, glucocorticoid-mediated effects become more dominant regulating energy supplementation under extended elevated energetic needs. In consequence, extended stress may lead to pathology-promoting neuronal, immune and metabolic adaptations. it also ensures that the body's energy supply lines do not run dry by increasing appetite and promoting the capacity of energy stores such as the liver and adipose tissues to refill or even increase their capacities (McEwen 2017). Important factors in this response are GCs and the appetite-promoting stomach-secreted peptide ghrelin. Elevated central GCs increase expression of the orexigenic hypothalamic neuropeptide NPY via inhibition of CRH (Zakrzewska et al. 1999). NPY also decreases anxiety and has been implicated in emotional eating (Kim et al. 2003, Yehuda et al. 2006). Activation of the HPA axis further upregulates the central release of endogenous opioids (O'Hare et al. 2004). Opioids decrease activity of the HPA axis, thus attenuating over-shooting stress responses (Kreek \& Koob 1998). At the same time, they increase palatable food intake and vice versa. If stress becomes chronic and eating becomes associated with stress coping, highly palatable food may become addictive (Volkow et al. 2017). Exposure to chronic social defeat results in elevated plasma concentrations of ghrelin that remain high long after the end of the stress intervention itself. In the pituitary, ghrelin further amplifies the activity of the HPA axis (Spencer et al. 2012). In the brain, ghrelin acts on various sites to attenuate anxiety and depressivelike behaviors (Lutter et al. 2008, Spencer et al. 2012). It also potently increases appetite through activation of orexigenic neurons in the mediobasal hypothalamus (Nakazato et al. 2001, Wren et al. 2001).

In a more natural environment, in which it may take a certain effort to ensure energy supplies, these changes in the regulation of energy utilization enable the body to survive through extended stress periods. Metabolic setpoints, that is, regulatory 'references' that enable the system to approximate a physiological state of homeostasis. In our modern society, however, we have no problems refilling our energy stores and the stimulation of appetite during extended stress easily overshoots physiological demands, promoting weight gain and adiposity (Razzoli et al. 2017). Moreover, unlike our ancestors, modern society often puts us under stressful psychological situations for months and years, for example, in competition for social and professional recognition, which has been shown to add an additional level of stress-related wear out (Cohen et al. 2007).

The perception of stress is influenced by experiences and genetics. When the brain perceives stress over extended time spans, physiological and behavioral responses are initiated leading to allostasis, that is, a shift in homeostatic setpoints, and adaptation. Over time, such allostatic load can accumulate and have adverse 
effects on various organ systems, leading to disease (Suvarna et al. 2020). In the CNS, chronic stress promotes the development of depression and neurodegenerative processes (Swaab et al. 2005). In the periphery, chronic stress adaptations cause obesity, cardiovascular complications, and impaired immune responses (Steptoe \& Kivimäki 2012, Dumbell et al. 2016, Razzoli et al. 2017). It is difficult to say to which extent these effects may have an evolutionary explanation or simply reflect exhaustion of an overwhelmed stress coping system under unnatural conditions.

The main agents in the long-term metabolic effects of chronic stress are GCs acting through binding to, both, glucocorticoid (GR) and mineralocorticoid nuclear receptors (MR) and eliciting transcriptional adaptive programs in peripheral tissues and the CNS (Reul \& de Kloet 1985). Chronic stress is a major risk factor for obesity and metabolic diseases. However, the relationship between stress hormones and energy metabolism is complex. For example, while some people increase food intake and body weight during stress, others show the opposite phenotype with reduced eating and weight loss (Harris 2015). Moreover, stress-induced hyperphagy is not necessarily followed by an increase in adiposity and body mass, suggesting that mechanisms to regulate energy consumption are activated at the same time (Dallman et al. 2003). In part, this may be explained by conflicting responses of the autonomic and the endocrine axis stress mediator systems. GCs boost energy consumption and inhibit energy expenditure to promote a positive energy balance. In contrast, sympathetically activated beta-adrenergic receptors increase energy expenditure by activating thermogenesis in brown adipose tissue (BAT) to favor a negative energy balance - a process that is suppressed by GCs (Hardwick et al. 1989). Therefore, stress may promote weight gain only if hyperphagy prevails (Dallman et al. 2003). In the presence of stressinduced hypophagy - or if BAT recruitment dominates weight loss will result. Despite these clear effects of stress on metabolic regulation, only few molecular mediators at the interface between stress and metabolic regulation have been discovered. Importantly, circadian clocks may play an important role in this interaction.

\section{The circadian clock system}

Circadian clocks have evolved to anticipate recurring changes in environmental conditions brought about by the Earth's rotation around its axis. In mammals, molecular clocks are found in all tissues and cells of the body. They are coordinated by a master clock residing in the hypothalamic suprachiasmatic nucleus (SCN) (Reppert $\&$ Weaver 2002). The SCN receives projections from intrinsically photosensitive ganglion cells expressing the blue-light sensitive photopigment melanopsin (OPN4). Through these projections, SCN neuronal firing rhythms are synchronized with the external light-darkness cycle (Lucas et al. 2012). Coordination of clock function in non-SCN central and peripheral tissues occurs through multiple pathways including endocrine, autonomic and behavioral outputs (Astiz et al. 2019). Of note, GCs have been implicated in this systemic coordination of circadian clock function. Treatment with GR agonists can reset clocks in vitro and in vivo, while genetic or pharmacologic alteration of GR signaling affects clock network resetting after phase-shifting stimuli (Balsalobre et al. 2000, Kiessling et al. 2010). In their potential to affect clock function in different tissues, GCs are very similar to another endocrine clock factor, melatonin (Pfeffer et al. 2018). Interestingly though, neither the loss of melatonin nor GC function markedly interferes with circadian clock network organization in mice, suggesting highly redundant means of systems coordination in the mammalian clock system (Astiz et al. 2019).

At the molecular level, circadian clocks are comprised of interlocked transcriptional-translational feedback loops (TTLs) involving a set of clock genes and proteins (Takahashi 2017). In the mammalian core TTL, the transcription factor dimer circadian locomotor output cycles kaput (CLOCK, which may in some tissues be replaced by neuronal PAS protein 2 - NPAS2)/brain and muscle ANRT-like 1 (BMAL1/ARNTL) activates expression of three period (Per1-3) and two cryptochrome genes (Cry1/2) during the day. PER and CRY proteins dimerize and, toward the end of the day, translocate into the nucleus where they inhibit CLOCK/BMAL1, thus shutting down their own transcription. Toward the end of the night, PER and CRY proteins are degraded resulting in a disinhibition of CLOCK/BMAL1 transactivation and a new molecular circadian cycle. The period of this TTL is modulated by several post-translational modifiers and by additional feedback loops involving further transcription factors such as albumin D-site binding protein (DBP) and reverse erythroblastoma alpha/beta (REV-ERBa/b, aka NR1D1/2) that affect abundance, localization, and turnover of the main TTL components (Buhr \& Takahashi 2013, Takahashi 2017).

The rhythm in clock gene transcription is translated into physiologically meaningful signals through https://joe.bioscientifica.com https://doi.org/10.1530/JOE-20-0124 (c) 2020 Society for Endocrinology Published by Bioscientifica Ltd. Printed in Great Britain 
tissue-specific transcriptional programs via circadian promoter elements such as enhancer (E-) boxes, albumin $\mathrm{D}$ site (D-) boxes and ROREs (retinoic acid-related orphan receptor response elements) (Ukai \& Ueda 2010) (Fig. 2). It is estimated that between 5 and $10 \%$ of protein-coding genes in a given tissue - 40-50\% across the whole body are expressed with a circadian rhythm (Zhang et al. 2014). Of note, just like the delayed-action GC-mediated stress response, circadian clock regulation acts through slow, transcription/translation-dependent alterations of the cellular enzymatic setup. Thus, just like GCs, the clock system is poorly equipped to respond to rapid changes in the environment, but rather serves to adapt the body to gradual or predictable alterations in demands.

\section{Clocks and metabolism}

Circadian clocks and energy metabolism are mutually linked to each other. Circadian disruption - either genetically or through external perturbations such as shift work, sleep curtailment, or nocturnal light pollution - is an independent risk factor for the development of metabolic disorders, from obesity and type- 2 diabetes to cardiovascular complications and even cancer (Levi \& Schibler 2007, Ramsey et al. 2007). Sleep curtailment

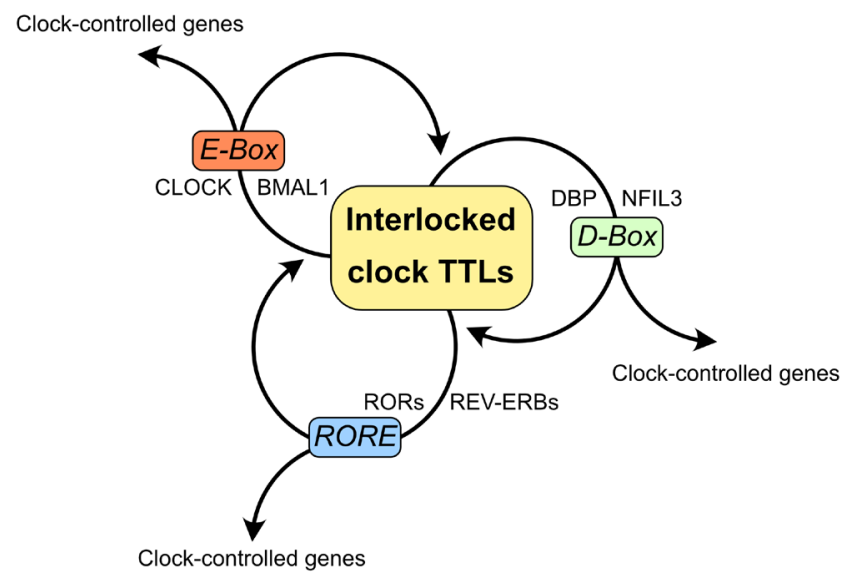

Figure 2

Coordination of cellular physiology through clock-controlled genes. The interlocked system of transcriptional-translational feedback loops (TTLs) comprising the cellular circadian clock regulates cellular function through the coordination of tissue-specific transcriptional programs and circadian promoter elements such as E-boxes, D-boxes and ROREs. E-boxes are activated by the clock proteins CLOCK (circadian locomotor output cycles kaput) and BMAL1 (brain and muscle ANRT-like 1); D-boxes by DBP (albumin D-site binding protein) and NFIL3 (nuclear factor, interleukin 3 regulated); and RORES by ROR (retinoid orphan receptor) and REV-ERB (reverse erythroblastoma) proteins. The combination of these circadian regulatory elements in the promoters of clock-controlled genes defines their phase of expression.

(C) 2020 Society for Endocrinology Published by Bioscientifica Ltd. Printed in Great Britain has been shown to rapidly reduce insulin sensitivity and affect appetite and high-energy food craving in laboratory studies (Reutrakul \& Van Cauter 2018). Animal experiments show that circadian clocks are important regulators of glucose and lipid handling and storage. For example, pancreatic b-cell clocks control insulin secretion, while adipose tissue clocks regulate lipolytic triglyceride breakdown and fatty acid release which, in turn, affects central circuits of appetite regulation (Paschos et al. 2012, Shostak et al. 2013, Perelis et al. 2015) (Fig. 3).

At the cellular level, circadian clocks are involved in the regulation of mitochondrial function and, hence, ATP production. Important enzymes of carbohydrate and lipid metabolism such as phosphenol pyruvate carboxykinase (PEPCK), apolipoprotein A4 (APOA4), and fatty acid synthase (FAS), among many others, are direct transcriptional targets of the circadian clock machinery (Zhang et al. 2014). As one example, in mouse liver, $16 \%$ of all protein-coding genes were found to be rhythmically expressed, though only a fraction of these seem to be directly regulated by the local clock machinery (Zhang et al. 2014, Greenwell et al. 2019). Others respond rather to systemic rhythmic factors such as hormones, feeding-related signals or body temperature (Harder \& Oster 2020). This complex interaction of external and local signal in the temporal regulation of the metabolic

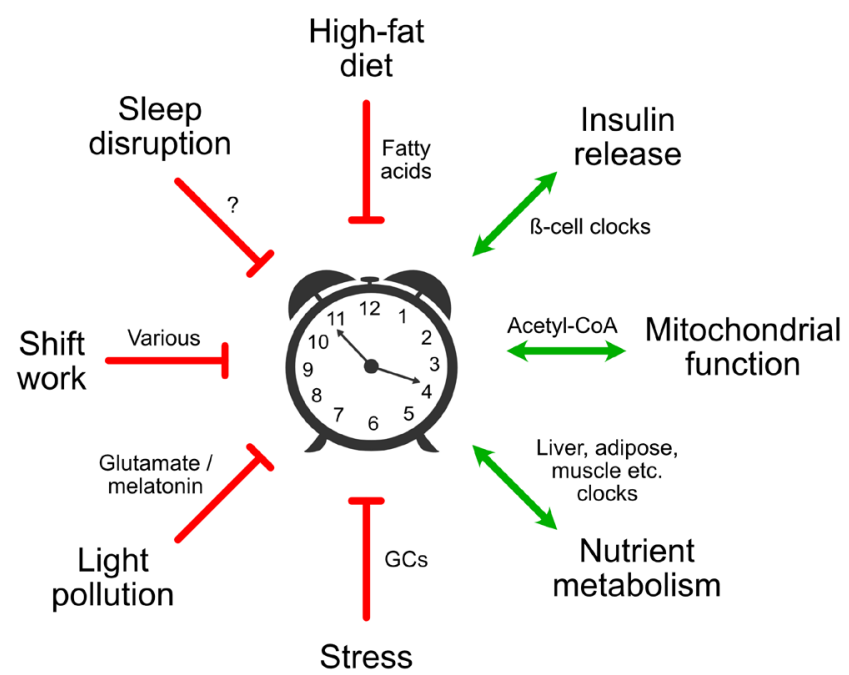

\section{Figure 3}

Chronodisruption alters energy metabolism. Several typical conditions of our modern 24-h society are capable of disrupting circadian rhythms through interaction with central and peripheral tissue clocks. These effects are mediated by endocrine factors such as glucocorticoids (GCs) or melatonin, but also through metabolites and neuronal activity. The circadian clock system and energy metabolism influence each other through rhythmic coordination of metabolic factors and cellular metabolism. For more details see the 'Clocks and metabolism' section. 
machinery suggests two things: metabolic tissue functions adapt to acute external demands but, at the same time, are subject to temporal modulation by the endogenous timing system. The clock ensures baseline adaptation to recurring and, thus, predictable changes in metabolic demands along the day while also temporally modulating - or gating - responsiveness of the system to external stimuli. At the same time, the system remains principally sensitive to less predictable changes. In line with this, external perturbation of circadian regulation often has more profound effects on metabolic homeostasis than genetic dysfunction of the local clock machinery (MeyerKovac et al. 2017, Heyde \& Oster 2020).

Interestingly, changes in metabolic state can feedback on clock function at several levels, thus altering tissue gene expression programs, but also circadian rhythms of behavior such as sleep or food intake. Switching mice from a standard low-fat chow to a Western style high-fat diet disrupts diurnal food intake profiles and rhythms of gene expression in several tissues and even slows down the SCN pacemaker (Kohsaka et al. 2007). This crosstalk has important implications for real-life situations of chronodisruption, for example, in shift workers. Behavioral intervention studies in rodents and humans have shown, for example, that stabilizing circadian feeding/fasting rhythms may have substantial metabolic benefits under obesogenic conditions (Chaix et al. 2014, Gill \& Panda 2015, Meyer-Kovac et al. 2017). Transgenic mouse studies suggest that the effects of, for example, time restricted feeding patterns on general well-being and health may even overcome genetic disruptions of the core clock machinery (Chaix et al. 2019).

At the cellular level, changes in metabolic state can directly affect the function of the circadian TTL. REV-ERBs are ligands for the metabolic sensor heme, and the capacity of CLOCK(NPAS2)/BMAL1 dimers to bind DNA and activate transcription depends strongly on the cellular redox state (Rutter et al. 2001, Yin et al. 2007). In this way, acute oxidative changes upon food intake may reset molecular clock gene rhythms and downstream cellular metabolic processes. Interestingly, the timing of food intake has strong effects on clock function in peripheral tissues. In extreme situations such as repeated rest phase feeding this may lead to a complete uncoupling of the peripheral clock machinery from the SCN pacemaker that stays locked to the external lightdarkness cycle (Damiola et al. 2000). Such state of internal desynchrony would result in a temporal mismatch of appetite regulatory circuits and metabolic tissue networks which, under modern conditions of easy food access, alters metabolic setpoints promoting hyperphagy and obesity. Indeed, work in rodents has shown that restoring circadian network coordination positively affects energy homeostasis under obesogenic conditions (West et al. 2017, Kolbe et al. 2019).

\section{Clocks and stress}

The mechanisms of systemic circadian entrainment are still poorly understood. As outlined previously, we know that the SCN uses both humoral and neural pathways to transmit time information across the clock network (Astiz et al. 2019). Among the best studied humoral mediators of circadian entrainment are GCs. Under non-stressed conditions, circulating GC levels show robust diurnal rhythmicity peaking at the beginning of the active phase (i.e. in the morning in diurnal humans and in the evening in nocturnal rodents). Circadian GC rhythms are involved in the coordination of clock function in central and peripheral tissues (Oster et al. 2016). The circadian control of GC secretion results from an interaction between the SCN and tissue clocks along the HPA axis (Leliavski et al. 2015) (Fig. 4). The SCN controls the rhythmic secretion of the adrenocorticotropic hormone (ACTH) from the pituitary gland via regulating the release of corticotropinreleasing hormone $(\mathrm{CRH})$ and arginine vasopressin (AVP)

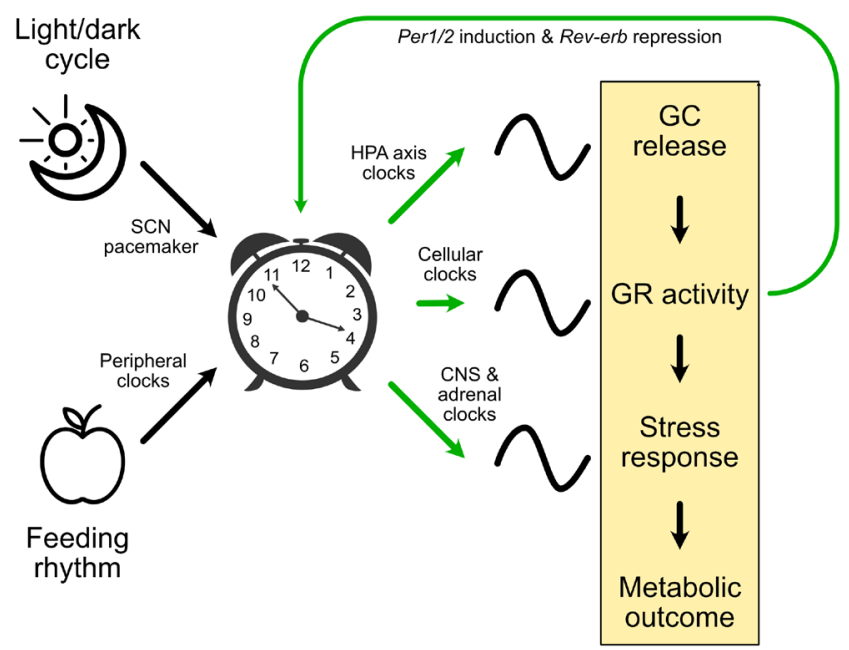

\section{Figure 4}

Circadian gating of the stress response. Circadian clocks are synchronized by external zeitgebers such as light (via the SCN pacemaker) or food (via peripheral tissue clocks). The circadian clock network affects stress responses at the level of GC baseline release, GR abundance and activity, and acute stress responses, for example, by regulating the sensitivity of the adrenal steroidogenic machinery to ACTH stimulation. Importantly, stress can also feedback on clock function through GC/GR-mediated regulation of clock gene transcription. 
from the paraventricular nucleus of the hypothalamus (PVN). ACTH, in turn, promotes GC biosynthesis and release from zona fasciculata cells of the adrenal cortex. Through the autonomic nervous system, the SCN at the same time synchronizes adrenal cellular clocks to regulate the time-of-day dependent sensitivity of the adrenal steroidogenic machinery to ACTH stimulation (Oster et al. 2006). Phase coherence of these two principle arms of the stress axis circadian system is required for high-amplitude rhythmic secretion of GCs.

Coupling between the stress system and the circadian clock is similarly observed at the molecular level. Due to its high affinity for GCs, MR is constitutively activated under most physiological conditions (Reul \& de Kloet 1985). In contrast, GRs are only activated at higher GC concentrations that cause phasic reactions, that is, at the circadian peak or in acute stressful situations (de Kloet et al. 2005). Upon ligand binding, GR dimers translocate from the cytosol into the nucleus, where they bind to glucocorticoid-responsive element (GRE) motifs in regulatory regions of target genes, including several core clock genes such as Per1/2 (So et al. 2009, Reddy et al. 2012). In contrast, the Rev-erb $\alpha$ locus contains negative GREs that mediate GR trans-repression (Torra et al. 2000). Recent studies suggest that clock proteins and GR can also interact at the protein level. CLOCK has acetyl transferase activity and is capable of acetylating GR to reduce its DNA-binding capacity (Nader et al. 2009). CRY proteins bind GR directly (Lamia et al. 2011). Finally, the presence of REV-ERB $\alpha$ affects the nuclear translocation of GR upon GC binding through interaction with heat shock proteins (Okabe et al. 2016).

In the adrenal glands, GCs and clock genes further interact in the modulation of catecholamine biosynthesis and breakdown, thus strengthening the coupling between the circadian and the stress system. Transcription of the catecholamine breakdown enzyme monoamine oxidase I (MAOA) is a direct target of CLOCK/BMAL1 (Hampp et al. 2008). On the other hand, expression of the pacemaker enzyme of catecholamine biosynthesis, tyrosine hydroxylase (TH), is suppressed by REV-ERB $\alpha$ (Jager et al. 2014; but also see Lemos et al. 2007). GR regulates the expression of catechol-O-methyltransferase (COMT) involved in catecholamine catabolism (Lindley et al. 2005). In summary, interactions between GCs/GR and the clock machinery may affect both fast- and delayedresponse/chronic stress systems.

Classic animal studies suggest that the extent of a specific stress response strongly depends on the time of day (Zimmermann \& Critchlow 1967, Gibbs 1970,
Dunn et al. 1972, Gallant \& Brownie 1979). During the active phase, physical stressor exposure like hemorrhage (Lilly et al. 2000), hypoglycemia (Kalsbeek et al. 2003), or oxidative stress (Antoch et al. 2005, Fanjul-Moles \& LópezRiquelme 2016) results in a greater increase in circulating GCs than at other periods of the day. In contrast, during the inactive phase, restraint/immobilization, foot shock, or shaking stress results in a stronger increase in GC and ACTH release and in blood pressure (Bradbury et al. 1991, Gattermann \& Weinandy 1996, Mathias et al. 2000, Bernatova et al. 2002, Retana-Márquez et al. 2003, Gutiérrez-Mariscal et al. 2012). More experiments are needed to clarify how exactly time-of-day affects the responsiveness to stress. Similarly, there is evidence for a time-of-day dependent adaptive response to repeated or chronic stress. Along this line, genetic disruption of the circadian clock system in mice dramatically changes the baseline activity and responsiveness of the stress system. Mice lacking either BMAL1 or CLOCK show hypocortisolism and acute stress resistance at behavioral and hormonal levels (Turek et al. 2005, Leliavski et al. 2014). Less conclusively, for mice lacking specific genes of the negative branch of the circadian TTL both hyperand hypocortisolism have been reported (Dallmann et al. 2006, Lamia et al. 2011, Barclay et al. 2013). Of interest in the context of energy metabolism, stress responses are exaggerated under high-fat diet conditions - but only at certain times of the day (Appiakannan et al. 2019).

\section{Chronodisruption, chronic stress and metabolic consequences}

Chronodisruption, that is, the alteration of behavioral and physiological rhythms relative to the natural 24-h day cycle, is a common phenomenon in modern societies. The invention of electric lighting has paved the way into industrialism and the uncoupling of activity schedules from the natural light-darkness cycle. Shift work is increasingly prevalent with $20-30 \%$ of the total workforce operating under non-standard or rotating shift conditions in European, North American and East Asian countries (Brown et al. 2020). Another chronodisruptive factor is the internationalization of markets with increased transmeridian travel and communication.

As mentioned earlier, both chronodisruption and stress may have independent as well as interactive effects on energy metabolism. Chronodisruptive conditions such as shiftwork are perceived as psychological stressors per se (Faraut et al. 2013). In consequence, relative to 
non-shift workers, shift workers have a higher risk for numerous adverse stress-associated health outcomes such as cardiovascular and gastrointestinal disorders, obesity, and some types of cancer (Kecklund \& Axelsson 2016). Even more related to stress, individuals working in shifts suffer more from psychiatric disorders such as depression, anxiety, and alcohol abuse (Walker et al. 2020). Finally - and again very similar to chronic stress effects - shift work negatively impacts on neurocognitive performance (Devore et al. 2013). In modern work environments, chronodisruption and psychosocial stress are often so intricately entwined that it is rather difficult to dissociate stress-specific from chronodisruptive aspects of metabolic and other disorders in the clinics. The immune system as another shared target of both stress and clock programs may play an important role in this crosstalk. Dampened cortisol rhythms and weakened stress responses have been observed in patients with immune diseases such as bronchial asthma, allergic rhinitis, or sepsis (Fei et al. 2004, Lesur et al. 2010, Fidan et al. 2013). Vice versa, earlylife exposure to endotoxin reprograms the HPA axis in rats, leading to GC hypersensitivity (Shanks et al. 1995).

Chronic stress has significant adverse effects in humans and - under conditions of easy access to highcalorie food - promotes hyperphagy and the development of obesity and type-2 diabetes (Adam \& Epel 2007). Even under physiological conditions, GCs have anabolic functions in the liver, stimulating gluconeogenesis and glycogen storage. GCs also inhibit glucose utilization in many peripheral tissues. Together, this leads to an increase in blood glucose levels and stimulates insulin secretion (Oster et al. 2016). In consequence, transient GC boosts during acute stress episodes efficiently suppress appetite and may even lead to weight loss (Razzoli et al. 2017). In contrast, chronic stress increases appetite for high-calorie foods and hyperglycemia (Dallman et al. 2003). In addition, chronic stress-associated GC changes may decrease insulin sensitivity in many tissues, thus promoting the development of type-2 diabetes (Joseph \& Golden 2017). Finally, GC resistance is associated with reduced GR expression in adipose tissue and increased triglyceride storage due to suppressed lipolysis (Shen et al. 2017).

Considering this interaction, studies on social stress associated with circadian rhythm disorders are of great clinical interest. Repeated (non-social) experimental stress is more detrimental to rats when applied during the rest phase, that is, the day. Chronic mild stress promotes depressive and anxiety-related behaviors when used during the day, but not at night (Aslani et al. 2014).
Stress induced by exposure to cat odor, immobilization stress or tail shocks also has more detrimental effects when applied repeatedly during the inactive phase (Retana-Márquez et al. 2003, Cohen et al. 2015, Fonken et al. 2016).

A common mouse model for social stress with good translational relevance is the social defeat (also known as the resident intruder) paradigm, in which the experimental animal (the intruder) is placed for a short time in the home cage of a superior resident. Within seconds to minutes, this usually leads to submission with physical and social stress mimicking social conflicts in humans. Interestingly, most social defeat studies indicate a more harmful effect of nighttime stress, but metabolic effects are predominantly observed in response to stress during the inactive phase (Rybkin et al. 1997, Bartlang et al. 2012, 2014, 2015). In rats, stress during the active phase does not affect body weight, which indicates a circadian regulation of chronic/repeated stress responses (Gorka \& Adamik 1993). Adjustments to repeated social defeat stress in mice, on the other hand, occur more frequently during the active phase (Koch et al. 2016). Specifically, 19 days of social daytime stress in mice led to a transient reduction in bodyweight, but no alterations in HPA axis activity at the predicted time of social stressor exposure. In contrast, repeated nighttime stressor exposure led to alterations in food metabolization and reduced HPA axis activity with lower hormone concentrations at the time of predicted stressor exposure (Koch et al. 2016). Together, these data suggest a circadian gating of stress adaptation to predictable social defeat stress at the level of the HPA axis with impact on metabolic homeostasis.

Of note, most stress studies in rodents are done during normal laboratory hours, which is the inactive phase of nocturnal rodents. The inherent complexity of social stress paradigms and poor control for circadian effects may explain why results from different stress studies frequently yield contradictory results. We clearly need more time-controlled studies in humans to translate these findings into real-life recommendations and treatments.

\section{Conclusions}

Chronodisruption and psychosocial stress are hallmarks of modern societies. Both share common signaling components, most notably GCs, and - under chronic conditions - have very similar pathophysiological consequences such as immunosuppression and disruption of metabolic homeostasis. Assessing circadian 
clock function in the context of acute and chronic stress may yield important insight into the physiological underpinnings of this psychological concept. Considering the detrimental consequences of chronic stress exposure on metabolic - but also neurologic - function and well-being, the circadian system may provide promising inroads into improving established and developing new treatments for some of the most prevalent chronic pathologies of our modern societies such as major depression, obesity, and type- 2 diabetes. As a start, circadian time needs to be recognized as a potential confounder in stress studies and the clinics. On the other hand, alterations in the circadian timing system may serve as biomarkers of stress impact and as predictors of pathological outcome. Along the same line, interventions aimed at restoring normal circadian function such as light therapies, interval fasting, or pharmacological interventions may, through clockmediated impact on stress responses and metabolism, counteract the detrimental effects of stress at several levels. Finally, timing of unavoidable stressful events to specific times of the day may help with stress coping and improve well-being and performance, for example, at the workplace.

\section{Declaration of interest}

$\mathrm{H} \mathrm{O}$ has received presentation honoraria from AbbVie, Shire Pharma, and Novo Nordisk. H O holds a patent on GC manipulation circadian synchronization (US Patent \# 9,770,444).

\section{Funding}

This work was supported by grants of the German Research Foundation (DFG; HO353-7/1, HO353-10/1, GRK-1957) to H O. The funders had no influence on the research presented in this paper.

\section{Author contribution statement}

$\mathrm{HO}$ wrote the paper.

\section{References}

Adam TC \& Epel ES 2007 Stress, eating and the reward system. Physiology and Behavior 91 449-458. (https://doi.org/10.1016/j. physbeh.2007.04.011)

Antoch MP, Kondratov RV \& Takahashi JS 2005 Circadian clock genes as modulators of sensitivity to genotoxic stress. Cell Cycle 4 901-907. (https://doi.org/10.4161/cc.4.7.1792)

Appiakannan HS, Kestyus DR \& Weber ET 2019 Effects of high fat diet and chronic circadian challenge on glucocorticoid regulation in C57BL/6J mice. Physiology and Behavior 204 100-105. (https://doi. org/10.1016/j.physbeh.2019.01.014)
Aslani S, Harb MR, Costa PS, Almeida OFX, Sousa N \& Palha JA 2014 Day and night: diurnal phase influences the response to chronic mild stress. Frontiers in Behavioral Neuroscience 8 82. (https://doi. org/10.3389/fnbeh.2014.00082)

Astiz M, Heyde I \& Oster H 2019 Mechanisms of communication in the mammalian circadian timing system. International Journal of Molecular Sciences 20 343. (https://doi.org/10.3390/ijms20020343)

Balsalobre A, Brown SA, Marcacci L, Tronche F, Kellendonk C, Reichardt HM, Schütz G \& Schibler U 2000 Resetting of circadian time in peripheral tissues by glucocorticoid signaling. Science $\mathbf{2 8 9}$ 2344-2347. (https://doi.org/10.1126/science.289.5488.2344)

Barclay JL, Shostak A, Leliavski A, Tsang AH, Jöhren O, Müller-Fielitz H, Landgraf D, Naujokat N, van der Horst GTJ \& Oster H 2013 High-fat diet-induced hyperinsulinemia and tissue-specific insulin resistance in Cry-deficient mice. American Journal of Physiology: Endocrinology and Metabolism 304 E1053-E1063. (https://doi.org/10.1152/ ajpendo.00512.2012)

Bartlang MS, Neumann ID, Slattery DA, Uschold-Schmidt N, Kraus D, Helfrich-Förster C \& Reber SO 2012 Time matters: pathological effects of repeated psychosocial stress during the active, but not inactive, phase of male mice. Journal of Endocrinology 215 425-437. (https:// doi.org/10.1530/JOE-12-0267)

Bartlang MS, Savelyev SA, Johansson AS, Reber SO, Helfrich-Förster C \& Lundkvist GBS 2014 Repeated psychosocial stress at night, but not day, affects the central molecular clock. Chronobiology International 31 996-1007. (https://doi.org/10.3109/07420528.2014.940085)

Bartlang MS, Oster H \& Helfrich-Förster C 2015 Repeated psychosocial stress at night affects the circadian activity rhythm of male mice. Journal of Biological Rhythms 30 228-241. (https://doi. org/10.1177/0748730415576192)

Bernatova I, Key MP, Lucot JB \& Morris M 2002 Circadian differences in stress-induced pressor reactivity in mice. Hypertension 40 768-773. (https://doi.org/10.1161/01.hyp.0000036405.27562.02)

Bradbury MJ, Cascio CS, Scribner KA \& Dallman MF 1991 Stress-induced adrenocorticotropin secretion: diurnal responses and decreases during stress in the evening are not dependent on corticosterone. Endocrinology 128 680-688. (https://doi.org/10.1210/endo-128-2-680)

Brown JP, Martin D, Nagaria Z, Verceles AC, Jobe SL \& Wickwire EM 2020 Mental health consequences of shift work: an updated review. Current Psychiatry Reports 22 7. (https://doi.org/10.1007/s11920-020-1131-z)

Buhr ED \& Takahashi JS 2013 Molecular components of the Mammalian circadian clock. Handbook of Experimental Pharmacology 217 3-27. (https://doi.org/10.1007/978-3-642-25950-0_1)

Chaix A, Zarrinpar A, Miu P \& Panda S 2014 Time-restricted feeding is a preventative and therapeutic intervention against diverse nutritional challenges. Cell Metabolism 20 991-1005. (https://doi.org/10.1016/j. cmet.2014.11.001)

Chaix A, Lin T, Le HD, Chang MW \& Panda S 2019 Time-restricted feeding prevents obesity and metabolic syndrome in mice lacking a circadian clock. Cell Metabolism 29 303.e4-319.e4. (https://doi. org/10.1016/j.cmet.2018.08.004)

Chen CY, Logan RW, Ma T, Lewis DA, Tseng GC, Sibille E \& McClung CA 2016 Effects of aging on circadian patterns of gene expression in the human prefrontal cortex. PNAS 113 206-211. (https://doi. org/10.1073/pnas.1508249112)

Cohen S, Janicki-Deverts D \& Miller GE 2007 Psychological stress and disease. JAMA 298 1685-1687. (https://doi.org/10.1001/ jama.298.14.1685)

Cohen S, Vainer E, Matar MA, Kozlovsky N, Kaplan Z, Zohar J, Mathé AA \& Cohen H 2015 Diurnal fluctuations in HPA and neuropeptide Y-ergic systems underlie differences in vulnerability to traumatic stress responses at different zeitgeber times. Neuropsychopharmacology 40 774-790. (https://doi.org/10.1038/npp.2014.257)

Cole MA, Kalman BA, Pace TW, Topczewski F, Lowrey MJ \& Spencer RL 2000 Selective blockade of the mineralocorticoid receptor impairs hypothalamic-pituitary-adrenal axis expression of habituation. Journal https://joe.bioscientifica.com

https://doi.org/10.1530/JOE-20-0124 (c) 2020 Society for Endocrinology Published by Bioscientifica Ltd. 
of Neuroendocrinology 12 1034-1042. (https://doi.org/10.1046/j.13652826.2000.00555.x)

Dallman MF, Pecoraro N, Akana SF, La Fleur SE, Gomez F, Houshyar H, Bell ME, Bhatnagar S, Laugero KD \& Manalo S 2003 Chronic stress and obesity: a new view of 'comfort food'. PNAS 100 11696-11701. (https://doi.org/10.1073/pnas.1934666100)

Dallmann R, Touma C, Palme R, Albrecht U \& Steinlechner S 2006 Impaired daily glucocorticoid rhythm in Per1 (Brd) mice. Journal of Comparative Physiology: A, Neuroethology, Sensory, Neural, and Behavioral Physiology 192 769-775. (https://doi.org/10.1007/s00359006-0114-9)

Damiola F, Le Minh N, Preitner N, Kornmann B, Fleury-Olela F \& Schibler U 2000 Restricted feeding uncouples circadian oscillators in peripheral tissues from the central pacemaker in the suprachiasmatic nucleus. Genes and Development 14 2950-2961. (https://doi. org/10.1101/gad.183500)

de Kloet ER, Joëls M \& Holsboer F 2005 Stress and the brain: from adaptation to disease. Nature Reviews: Neuroscience 6 463-475. (https:// doi.org/10.1038/nrn1683)

Devore EE, Grodstein F \& Schernhammer ES 2013 Shift work and cognition in the Nurses' Health Study. American Journal of Epidemiology 178 1296-1300. (https://doi.org/10.1093/aje/kwt214)

Douglas WW \& Rubin RP 1961 Mechanism of nicotinic action at the adrenal medulla: calcium as a link in stimulus-secretion coupling. Nature 192 1087-1089. (https://doi.org/10.1038/1921087b0)

Dumbell R, Matveeva O \& Oster H 2016 Circadian clocks, stress, and immunity. Frontiers in Endocrinology 7 37. (https://doi.org/10.3389/ fendo.2016.00037)

Dunn J, Scheving L \& Millet P 1972 Circadian variation in stress-evoked increases in plasma corticosterone. American Journal of Physiology 223 402-406. (https://doi.org/10.1152/ajplegacy.1972.223.2.402)

Ellis BJ \& Del Giudice M 2019 Developmental adaptation to stress: an evolutionary perspective. Annual Review of Psychology 70 111-139. (https://doi.org/10.1146/annurev-psych-122216-011732)

Fanjul-Moles ML \& López-Riquelme GO 2016 Relationship between oxidative stress, circadian rhythms, and AMD. Oxidative Medicine and Cellular Longevity 2016 7420637. (https://doi. org/10.1155/2016/7420637)

Faraut B, Bayon V \& Léger D 2013 Neuroendocrine, immune and oxidative stress in shift workers. Sleep Medicine Reviews 17 433-444. (https://doi.org/10.1016/j.smrv.2012.12.006)

Fei GH, Liu RY, Zhang ZH \& Zhou JN 2004 Alterations in circadian rhythms of melatonin and cortisol in patients with bronchial asthma. Acta Pharmacologica Sinica 25 651-656. (available at: http://www. chinaphar.com/article/view/8196)

Fidan V, Alp HH, Kalkandelen S \& Cingi C 2013 Melatonin and cortisol rhythm in patients with extensive nasal polyposis. American Journal of Otolaryngology 34 61-64. (https://doi.org/10.1016/j. amjoto.2012.09.001)

Figueiredo HF, Bodie BL, Tauchi M, Dolgas CM \& Herman JP 2003 Stress integration after acute and chronic predator stress: differential activation of central stress circuitry and sensitization of the hypothalamo-pituitary-adrenocortical axis. Endocrinology 144 5249-5258. (https://doi.org/10.1210/en.2003-0713)

Fonken LK, Weber MD, Daut RA, Kitt MM, Frank MG, Watkins LR \& Maier SF 2016 Stress-induced neuroinflammatory priming is time of day dependent. Psychoneuroendocrinology 66 82-90. (https://doi. org/10.1016/j.psyneuen.2016.01.006)

Ford ND, Patel SA \& Narayan KMV 2017 Obesity in low- and middleincome countries: burden, drivers, and emerging challenges. Annual Review of Public Health 38 145-164. (https://doi.org/10.1146/annurevpublhealth-031816-044604)

Gallant S \& Brownie AC 1979 Serum corticosteroids at the high and low points of the circadian rhythm in rats with regenerating adrenals. Life Sciences 24 1097-1101. (https://doi.org/10.1016/0024-3205(79)90043-2)
Gattermann R \& Weinandy R 1996 Time of day and stress response to different stressors in experimental animals. Part I: Golden hamster (Mesocricetus auratus Waterhouse, 1839) Journal of Experimental Animal Science 38 66-76.

Gibbs FP 1970 Circadian variation of ether-induced corticosterone secretion in the rat. American Journal of Physiology 219 288-292. (https://doi.org/10.1152/ajplegacy.1970.219.2.288)

Gill S \& Panda S 2015 A smartphone App reveals erratic diurnal eating patterns in humans that can be modulated for health benefits. Cell Metabolism 22 789-798. (https://doi.org/10.1016/j. cmet.2015.09.005)

Gorka Z \& Adamik P 1993 The effect of reserpine and stress on feeding behaviour in the light and dark phases of the diurnal cycle in rats. Journal of Pharmacy and Pharmacology 45 137-138. (https://doi. org/10.1111/j.2042-7158.1993.tb03698.x)

Greenwell BJ, Trott AJ, Beytebiere JR, Pao S, Bosley A, Beach E, Finegan P, Hernandez C \& Menet JS 2019 Rhythmic food intake drives rhythmic gene expression more potently than the hepatic circadian clock in mice. Cell Reports 27 649.e5-657.e5. (https://doi.org/10.1016/j. celrep.2019.03.064)

Gutiérrez-Mariscal M, Sánchez E, Rebolledo-Solleiro D, García-Vázquez AI, Cote-Vélez A, Acasuso-Rivero C, Charli JL \& Joseph-Bravo P 2012 The acute response of the amygdalar TRH system to psychogenic stressors varies dependent on the paradigm and circadian condition. Brain Research 1452 73-84. (https://doi.org/10.1016/j.brainres.2012.02.071)

Hampp G, Ripperger JA, Houben T, Schmutz I, Blex C, Perreau-Lenz S, Brunk I, Spanagel R, Ahnert-Hilger G, Meijer JH, et al. 2008 Regulation of monoamine oxidase A by circadian-clock components implies clock influence on mood. Current Biology 18 678-683. (https://doi. org/10.1016/j.cub.2008.04.012)

Harder L \& Oster H 2020 The Tissue Clock Network: Driver and gatekeeper of circadian physiology: circadian rhythms are integrated outputs of central and peripheral tissue clocks interacting in a complex manner - from drivers to gatekeepers. BioEssays $\mathbf{4 2}$ e1900158. (https://doi.org/10.1002/bies.201900158)

Hardwick AJ, Linton EA \& Rothwell NJ 1989 Thermogenic effects of the antiglucocorticoid RU-486 in the rat: involvement of corticotropinreleasing factor and sympathetic activation of brown adipose tissue. Endocrinology 124 1684-1688. (https://doi.org/10.1210/endo-124-41684)

Harris RBS 2015 Chronic and acute effects of stress on energy balance: are there appropriate animal models? American Journal of Physiology: Regulatory, Integrative and Comparative Physiology 308 R250-R265. (https://doi.org/10.1152/ajpregu.00361.2014)

Hering D, Lachowska K \& Schlaich M 2015 Role of the sympathetic nervous system in stress-mediated cardiovascular disease. Current Hypertension Reports 17 80. (https://doi.org/10.1007/s11906-015-0594-5)

Herman JP, Adams D \& Prewitt C 1995 Regulatory changes in neuroendocrine stress-integrative circuitry produced by a variable stress paradigm. Neuroendocrinology 61 180-190. (https://doi. org/10.1159/000126839)

Herold KC, Majzoub JA, Melmed S, Pendergrass M \& Schlumberger M 2015 Endocrinology research-reflecting on the past decade and looking to the next. Nature Reviews: Endocrinology 11 672-680. (https://doi.org/10.1038/nrendo.2015.164)

Heyde I \& Oster H 2020 Network-like organization of the circadian system regulates metabolic homeostasis. Obesity 28 S8-S9. (https:// doi.org/10.1002/oby.22773)

Huang CJ, Webb HE, Zourdos MC \& Acevedo EO 2013 Cardiovascular reactivity, stress, and physical activity. Frontiers in Physiology 4314. (https://doi.org/10.3389/fphys.2013.00314)

Imaki T, Nahan JL, Rivier C, Sawchenko PE \& Vale W 1991 Differential regulation of corticotropin-releasing factor mRNA in rat brain regions by glucocorticoids and stress. Journal of Neuroscience 11 585-599. (https://doi.org/10.1523/JNEUROSCI.11-03-00585.1991) https://joe.bioscientifica.com https://doi.org/10.1530/JOE-20-0124 (c) 2020 Society for Endocrinology Published by Bioscientifica Ltd. Printed in Great Britain 
Jager J, O’Brien WT, Manlove J, Krizman EN, Fang B, Gerhart-Hines Z, Robinson MB, Klein PS \& Lazar MA 2014 Behavioral changes and dopaminergic dysregulation in mice lacking the nuclear receptor Reverbo. Molecular Endocrinology 28 490-498. (https://doi.org/10.1210/ me.2013-1351)

Joseph JJ \& Golden SH 2017 Cortisol dysregulation: the bidirectional link between stress, depression, and type 2 diabetes mellitus. Annals of the New York Academy of Sciences 1391 20-34. (https://doi.org/10.1111/ nyas.13217)

Kalsbeek A, Ruiter M, La Fleur SE, Van Heijningen C \& Buijs RM 2003 The diurnal modulation of hormonal responses in the rat varies with different stimuli. Journal of Neuroendocrinology 15 1144-1155. (https:// doi.org/10.1111/j.1365-2826.2003.01112.x)

Kecklund G \& Axelsson J 2016 Health consequences of shift work and insufficient sleep. BMJ 355 i5210. (https://doi.org/10.1136/bmj. i5210)

Kiessling S, Eichele G \& Oster H 2010 Adrenal glucocorticoids have a key role in circadian resynchronization in a mouse model of jet lag. Journal of Clinical Investigation 120 2600-2609. (https://doi. org/10.1172/JCI41192)

Kim H, Whang WW, Kim HT, Pyun KH, Cho SY, Hahm DH, Lee HJ \& Shim I 2003 Expression of neuropeptide Y and cholecystokinin in the rat brain by chronic mild stress. Brain Research 983 201-208. (https:// doi.org/10.1016/s0006-8993(03)03087-7)

Kirschbaum C, Pirke KM \& Hellhammer DH 1993 The 'Trier Social Stress Test' - a tool for investigating psychobiological stress responses in a laboratory setting. Neuropsychobiology 28 76-81. (https://doi org/10.1159/000119004)

Koch CE, Bartlang MS, Kiehn JT, Lucke L, Naujokat N, Helfrich-Förster C, Reber SO \& Oster H 2016 Time-of-day-dependent adaptation of the HPA axis to predictable social defeat stress. Journal of Endocrinology 231 209-221. (https://doi.org/10.1530/JOE-16-0163)

Kohsaka A, Laposky AD, Ramsey KM, Estrada C, Joshu C, Kobayashi Y, Turek FW \& Bass J 2007 High-fat diet disrupts behavioral and molecular circadian rhythms in mice. Cell Metabolism 6 414-421. (https://doi.org/10.1016/j.cmet.2007.09.006)

Kolbe I, Leinweber B, Brandenburger M \& Oster H 2019 Circadian clock network desynchrony promotes weight gain and alters glucose homeostasis in mice. Molecular Metabolism 30 140-151. (https://doi. org/10.1016/j.molmet.2019.09.012)

Kreek MJ \& Koob GF 1998 Drug dependence: stress and dysregulation of brain reward pathways. Drug and Alcohol Dependence $5123-47$. (https://doi.org/10.1016/s0376-8716(98)00064-7)

Lamia KA, Papp SJ, Yu RT, Barish GD, Uhlenhaut NH, Jonker JW, Downes M \& Evans RM 2011 Cryptochromes mediate rhythmic repression of the glucocorticoid receptor. Nature $\mathbf{4 8 0} 552-556$. (https://doi.org/10.1038/nature10700)

Leliavski A, Shostak A, Husse J \& Oster H 2014 Impaired glucocorticoid production and response to stress in Arntl-deficient male mice. Endocrinology 155 133-142. (https://doi.org/10.1210/en.2013-1531)

Leliavski A, Dumbell R, Ott V \& Oster H 2015 Adrenal clocks and the role of adrenal hormones in the regulation of circadian physiology. Journal of Biological Rhythms 30 20-34. (https://doi. org/10.1177/0748730414553971)

Lemos DR, Goodspeed L, Tonelli L, Antoch MP, Ojeda SR \& Urbanski HF 2007 Evidence for circadian regulation of activating transcription factor 5 but not tyrosine hydroxylase by the chromaffin cell clock. Endocrinology 148 5811-5821. (https://doi.org/10.1210/en.2007-0610)

Lesur O, Roussy JF, Chagnon F, Gallo-Payet N, Dumaine R, Sarret P, Chraibi A, Chouinard L \& Hogue B 2010 Proven infection-related sepsis induces a differential stress response early after ICU admission. Critical Care 14 R131. (https://doi.org/10.1186/cc9102)

Levi F \& Schibler U 2007 Circadian rhythms: mechanisms and therapeutic implications. Annual Review of Pharmacology and Toxicology 47 593-628. (https://doi.org/10.1146/annurev. pharmtox.47.120505.105208)
Lilly MP, Jones RO, Putney DJ \& Carlson DE 2000 Post-surgical recovery and time-of-day mask potentiated responses of ACTH to repeated moderate hemorrhage in conscious rats. Journal of Endocrinology 167 205-217. (https://doi.org/10.1677/joe.0.1670205)

Lindley SE, She X \& Schatzberg AF 2005 Monoamine oxidase and catechol-o-methyltransferase enzyme activity and gene expression in response to sustained glucocorticoids. Psychoneuroendocrinology 30 785-790. (https://doi.org/10.1016/j.psyneuen.2005.03.007)

Lucas RJ, Lall GS, Allen AE \& Brown TM 2012 How rod, cone, and melanopsin photoreceptors come together to enlighten the mammalian circadian clock. Progress in Brain Research 199 1-18. (https://doi.org/10.1016/B978-0-444-59427-3.00001-0)

Lutter M, Sakata I, Osborne-Lawrence S, Rovinsky SA, Anderson JG, Jung S, Birnbaum S, Yanagisawa M, Elmquist JK, Nestler EJ, et al. 2008 The orexigenic hormone ghrelin defends against depressive symptoms of chronic stress. Nature Neuroscience 11 752-753. (https:// doi.org/10.1038/nn.2139)

Makino S, Smith MA \& Gold PW 1995 Increased expression of corticotropin-releasing hormone and vasopressin messenger ribonucleic acid (mRNA) in the hypothalamic paraventricular nucleus during repeated stress: association with reduction in glucocorticoid receptor mRNA levels. Endocrinology 136 3299-3309. (https://doi. org/10.1210/endo.136.8.7628364)

Mamalaki E, Kvetnansky R, Brady LS, Gold PW \& Herkenham M 1992 Repeated immobilization stress alters tyrosine hydroxylase, corticotropin-releasing hormone and corticosteroid receptor messenger ribonucleic acid levels in rat brain. Journal of Neuroendocrinology 4 689-699. (https://doi. org/10.1111/j.1365-2826.1992.tb00220.x)

Martin KP \& Wellman CL 2011 NMDA receptor blockade alters stressinduced dendritic remodeling in medial prefrontal cortex. Cerebral Cortex 21 2366-2373. (https://doi.org/10.1093/cercor/bhr021)

Mathias S, Schiffelholz T, Linthorst AC, Pollmächer T \& Lancel M 2000 Diurnal variations in lipopolysaccharide-induced sleep, sickness behavior and changes in corticosterone levels in the rat. Neuroendocrinology 71 375-385. (https://doi.org/10.1159/000054558)

McEwen BS 2016 Stress-induced remodeling of hippocampal CA3 pyramidal neurons. Brain Research 1645 50-54. (https://doi. org/10.1016/j.brainres.2015.12.043)

McEwen BS 2017 Neurobiological and systemic effects of chronic stress. Chronic Stress 12470547017692328 . (https://doi. org/10.1177/2470547017692328)

Meyer-Kovac J, Kolbe I, Ehrhardt L, Leliavski A, Husse J, Salinas G, Lingner T, Tsang AH, Barclay JL \& Oster H 2017 Hepatic gene therapy rescues high-fat diet responses in circadian clock mutant mice. Molecular Metabolism 6 512-523. (https://doi.org/10.1016/j. molmet.2017.03.008)

Nader N, Chrousos GP \& Kino T 2009 Circadian rhythm transcription factor CLOCK regulates the transcriptional activity of the glucocorticoid receptor by acetylating its hinge region lysine cluster: potential physiological implications. FASEB Journal 23 1572-1583. (https://doi.org/10.1096/fj.08-117697)

Nakazato M, Murakami N, Date Y, Kojima M, Matsuo H, Kangawa K \& Matsukura S 2001 A role for ghrelin in the central regulation of feeding. Nature 409 194-198. (https://doi.org/10.1038/35051587)

O'Hare E, Shaw DL, Tierney KJ, E-m K, Levine AS \& Shephard RA 2004 Behavioral and neurochemical mechanisms of the action of mild stress in the enhancement of feeding. Behavioral Neuroscience 118 173-177. (https://doi.org/10.1037/0735-7044.118.1.173)

Okabe T, Chavan R, Fonseca Costa SS, Brenna A, Ripperger JA \& Albrecht U 2016 REV-ERB $\alpha$ influences the stability and nuclear localization of the glucocorticoid receptor. Journal of Cell Science $\mathbf{1 2 9}$ 4143-4154. (https://doi.org/10.1242/jcs.190959)

Oster H, Damerow S, Kiessling S, Jakubcakova V, Abraham D, Tian J, Hoffmann MW \& Eichele G 2006 The circadian rhythm of glucocorticoids is regulated by a gating mechanism residing in https://joe.bioscientifica.com

https://doi.org/10.1530/JOE-20-0124 (c) 2020 Society for Endocrinology Published by Bioscientifica Ltd. Printed in Great Britain 
the adrenal cortical clock. Cell Metabolism 4 163-173. (https://doi. org/10.1016/j.cmet.2006.07.002)

Oster H, Challet E, Ott V, Arvat E, de Kloet ER, Dijk D-J, Lightman S, Vgontzas A \& Van Cauter E 2016 The functional and clinical significance of the 24-h rhythm of circulating glucocorticoids. Endocrine Reviews 38 3-45. (https://doi.org/10.1210/er.2015-1080)

Paschos GK, Ibrahim S, Song WL, Kunieda T, Grant G, Reyes TM, Bradfield CA, Vaughan CH, Eiden M, Masoodi M, et al. 2012 Obesity in mice with adipocyte-specific deletion of clock component Arntl. Nature Medicine 18 1768-1777. (https://doi.org/10.1038/nm.2979)

Perelis M, Marcheva B, Ramsey KM, Schipma MJ, Hutchison AL, Taguchi A, Peek CB, Hong H, Huang W, Omura C, et al. 2015 Pancreatic $\beta$ cell enhancers regulate rhythmic transcription of genes controlling insulin secretion. Science $\mathbf{3 5 0}$ aac4250. (https://doi. org/10.1126/science.aac4250)

Pfeffer M, Korf HW \& Wicht H 2018 Synchronizing effects of melatonin on diurnal and circadian rhythms. General and Comparative Endocrinology 258 215-221. (https://doi.org/10.1016/j. ygcen.2017.05.013)

Pittendrigh CS 1993 Temporal organization: reflections of a Darwinian clock-watcher. Annual Review of Physiology 55 16-54. (https://doi. org/10.1146/annurev.ph.55.030193.000313)

Ramsey KM, Marcheva B, Kohsaka A \& Bass J 2007 The clockwork of metabolism. Annual Review of Nutrition 27 219-240. (https://doi. org/10.1146/annurev.nutr.27.061406.093546)

Razzoli M, Pearson C, Crow S \& Bartolomucci A 2017 Stress, overeating, and obesity: insights from human studies and preclinical models. Neuroscience and Biobehavioral Reviews 76 154-162. (https://doi. org/10.1016/j.neubiorev.2017.01.026)

Reddy TE, Gertz J, Crawford GE, Garabedian MJ \& Myers RM 2012 The hypersensitive glucocorticoid response specifically regulates period 1 and expression of circadian genes. Molecular and Cellular Biology 32 3756-3767. (https://doi.org/10.1128/MCB.00062-12)

Reppert SM \& Weaver DR 2002 Coordination of circadian timing in mammals. Nature 418 935-941. (https://doi.org/10.1038/ nature00965)

Retana-Márquez S, Bonilla-Jaime H, Vázquez-Palacios G, DomínguezSalazar E, Martínez-García R \& Velázquez-Moctezuma J 2003 Body weight gain and diurnal differences of corticosterone changes in response to acute and chronic stress in rats. Psychoneuroendocrinology 28 207-227. (https://doi.org/10.1016/s0306-4530(02)00017-3)

Reul JM \& de Kloet ER 1985 Two receptor systems for corticosterone in rat brain: microdistribution and differential occupation. Endocrinology 117 2505-2511. (https://doi.org/10.1210/endo-117-62505)

Reutrakul S \& Van Cauter E 2018 Sleep influences on obesity, insulin resistance, and risk of type 2 diabetes. Metabolism: Clinical and Experimental 84 56-66. (https://doi.org/10.1016/j. metabol.2018.02.010)

Russell G \& Lightman S 2019 The human stress response. Nature Reviews: Endocrinology 15 525-534. (https://doi.org/10.1038/s41574019-0228-0)

Rutter J, Reick M, Wu LC \& McKnight SL 2001 Regulation of clock and NPAS2 DNA binding by the redox state of NAD cofactors. Science 293 510-514. (https://doi.org/10.1126/science.1060698)

Rybkin II, Zhou Y, Volaufova J, Smagin GN, Ryan DH \& Harris RB 1997 Effect of restraint stress on food intake and body weight is determined by time of day. American Journal of Physiology 273 R1612-R1622. (https://doi.org/10.1152/ajpregu.1997.273.5.R1612)

Shanks N, Larocque S \& Meaney MJ 1995 Neonatal endotoxin exposure alters the development of the hypothalamic-pituitary-adrenal axis: early illness and later responsivity to stress. Journal of Neuroscience $\mathbf{1 5}$ 376-384. (https://doi.org/10.1523/JNEUROSCI.15-01-00376.1995)

Shen Y, Roh HC, Kumari M \& Rosen ED 2017 Adipocyte glucocorticoid receptor is important in lipolysis and insulin resistance due to exogenous steroids, but not insulin resistance caused by high fat feeding. Molecular Metabolism 6 1150-1160. (https://doi. org/10.1016/j.molmet.2017.06.013)

Shostak A, Meyer-Kovac J \& Oster H 2013 Circadian regulation of lipid mobilization in white adipose tissues. Diabetes 62 2195-2203. (https://doi.org/10.2337/db12-1449)

Snider KH, Sullivan KA \& Obrietan K 2018 Circadian regulation of hippocampal-dependent memory: circuits, synapses, and molecular mechanisms. Neural Plasticity 2018 7292540. (https://doi. org $/ 10.1155 / 2018 / 7292540)$

So AY-L, Bernal TU, Pillsbury ML, Yamamoto KR \& Feldman BJ 2009 Glucocorticoid regulation of the circadian clock modulates glucose homeostasis. PNAS 106 17582-17587. (https://doi.org/10.1073/ pnas.0909733106)

Spencer SJ, Xu L, Clarke MA, Lemus M, Reichenbach A, Geenen B, Kozicz T \& Andrews ZB 2012 Ghrelin regulates the hypothalamic-pituitaryadrenal axis and restricts anxiety after acute stress. Biological Psychiatry 72 457-465. (https://doi.org/10.1016/j.biopsych.2012.03.010)

Steptoe A \& Kivimäki M 2012 Stress and cardiovascular disease. Nature Reviews: Cardiology 9 360-370. (https://doi.org/10.1038/ nrcardio.2012.45)

Suvarna B, Suvarna A, Phillips R, Juster RP, McDermott B \& Sarnyai Z 2020 Health risk behaviours and allostatic load: a systematic review. Neuroscience and Biobehavioral Reviews 108 694-711. (https://doi. org/10.1016/j.neubiorev.2019.12.020)

Swaab DF, Bao AM \& Lucassen PJ 2005 The stress system in the human brain in depression and neurodegeneration. Ageing Research Reviews 4 141-194. (https://doi.org/10.1016/j.arr.2005.03.003)

Takahashi JS 2017 Transcriptional architecture of the mammalian circadian clock. Nature Reviews: Genetics 18 164-179. (https://doi. org/10.1038/nrg.2016.150)

Thome J, Densmore M, Frewen PA, McKinnon MC, Théberge J, Nicholson AA, Koenig J, Thayer JF \& Lanius RA 2017 Desynchronization of autonomic response and central autonomic network connectivity in posttraumatic stress disorder. Human Brain Mapping 38 27-40. (https://doi.org/10.1002/hbm.23340)

Timmermans S, Souffriau J \& Libert C 2019 A general introduction to glucocorticoid biology. Frontiers in Immunology 10 1545. (https://doi. org/10.3389/fimmu.2019.01545)

Torra IP, Tsibulsky V, Delaunay F, Saladin R, Laudet V, Fruchart JC, Kosykh V \& Staels B 2000 Circadian and glucocorticoid regulation of Rev-erbalpha expression in liver. Endocrinology 141 3799-3806. (https://doi.org/10.1210/endo.141.10.7708)

Tsigos C, Kyrou I, Kassi E \& Chrousos GP 2000 Stress, endocrine physiology and pathophysiology. In Endotext. South Dartmouth, MA USA: MDText.com, Inc. (available at: https://www.ncbi.nlm.nih.gov/ books/NBK278995/)

Turcu AF \& Auchus RJ 2015 Adrenal steroidogenesis and congenital adrenal hyperplasia. Endocrinology and Metabolism Clinics of North America 44 275-296. (https://doi.org/10.1016/j.ecl.2015.02.002)

Turek FW, Joshu C, Kohsaka A, Lin E, Ivanova G, McDearmon E, Laposky A, Losee-Olson S, Easton A, Jensen DR, et al. 2005 Obesity and metabolic syndrome in circadian clock mutant mice. Science 308 1043-1045. (https://doi.org/10.1126/science.1108750)

Ukai H \& Ueda HR 2010 Systems biology of mammalian circadian clocks. Annual Review of Physiology 72 579-603. (https://doi.org/10.1146/ annurev-physiol-073109-130051)

Volkow ND, Wise RA \& Baler R 2017 The dopamine motive system: implications for drug and food addiction. Nature Reviews: Neuroscience 18 741-752. (https://doi.org/10.1038/nrn.2017.130)

Walker WH, Walton JC, DeVries AC \& Nelson RJ 2020 Circadian rhythm disruption and mental health. Translational Psychiatry 10 28. (https:// doi.org/10.1038/s41398-020-0694-0)

West AC, Smith L, Ray DW, Loudon ASI, Brown TM \& Bechtold DA 2017 Misalignment with the external light environment drives metabolic and cardiac dysfunction. Nature Communications 8 417. (https://doi. org/10.1038/s41467-017-00462-2) https://joe.bioscientifica.com https://doi.org/10.1530/JOE-20-0124 (c) 2020 Society for Endocrinology Published by Bioscientifica Ltd. Printed in Great Britain 
Wong DL 2006 Epinephrine biosynthesis: hormonal and neural control during stress. Cellular and Molecular Neurobiology 26 891-900. (https:// doi.org/10.1007/s10571-006-9056-6)

Wren AM, Seal LJ, Cohen MA, Brynes AE, Frost GS, Murphy KG, Dhillo WS, Ghatei MA \& Bloom SR 2001 Ghrelin enhances appetite and increases food intake in humans. Journal of Clinical Endocrinology and Metabolism 86 5992. (https://doi.org/10.1210/ jcem.86.12.8111)

Yehuda R, Brand S \& Yang RK 2006 Plasma neuropeptide Y concentrations in combat exposed veterans: relationship to trauma exposure, recovery from PTSD, and coping. Biological Psychiatry 59 660-663. (https://doi.org/10.1016/j.biopsych.2005.08.027)

Yin L, Wu N, Curtin JC, Qatanani M, Szwergold NR, Reid RA, Waitt GM, Parks DJ, Pearce KH, Wisely GB, et al. 2007 Rev-erbalpha, a heme sensor that coordinates metabolic and circadian pathways. Science 318 1786-1789. (https://doi.org/10.1126/science.1150179)

Zakrzewska KE, Cusin I, Stricker-Krongrad A, Boss O, Ricquier D, Jeanrenaud B \& Rohner-Jeanrenaud F 1999 Induction of obesity and hyperleptinemia by central glucocorticoid infusion in the rat. Diabetes 48 365-370. (https://doi.org/10.2337/diabetes.48.2.365)

Zhang R, Lahens NF, Ballance HI, Hughes ME \& Hogenesch JB 2014 A circadian gene expression atlas in mammals: implications for biology and medicine. PNAS 111 16219-16224. (https://doi.org/10.1073/ pnas.1408886111)

Zimmermann E \& Critchlow V 1967 Effects of diurnal variation in plasma corticosterone levels on adrenocortical response to stress. Proceedings of the Society for Experimental Biology and Medicine 125 658-663. (https://doi.org/10.3181/00379727-125-32172)

Received in final form 24 June 2020

Accepted 23 July 2020

Accepted Manuscript published online 23 July 2020
(C) 2020 Society for Endocrinology Published by Bioscientifica Ltd. 